\title{
recildunds
}

Revista Cientifica Mundo de la Investigación y el Conocimiento

Sheyla Tamara Luna Martillo ${ }^{\text {a }}$; Diana Nathaly Chaguay Blacio ${ }^{\text {b }}$; Efrén Bryan

Barco Ramírez ${ }^{\mathrm{c}}$; Jorge Andrés Carbo Palacio ${ }^{\mathrm{d}}$

Neoplasia Cervicouterina: diagnóstico y tratamiento

Cervicouterin neoplasia: diagnosis and treatment

Revista Científica Mundo de la Investigación y el Conocimiento. Vol. 3 núm. 4., diciembre, ISSN: 2588-073X, 2019, pp. 3-28

DOI: $10.26820 /$ recimundo/3.(4).diciembre.2019.3-28

URL: http://recimundo.com/index.php/es/article/view/650

Código UNESCO: 3205 Medicina Interna

Tipo de Investigación: Artículo de Revisión

(C) RECIMUNDO; Editorial Saberes del Conocimiento, 2019

Recibido: 15/09/2019

Aceptado: 23/11/2019

Publicado: 30/12/2019

Correspondencia: sheytalumar@hotmail.com

a. Médico; Investigador Independiente; Guayaquil, Ecuador; sheytalumar@hotmail.com

b. Médico; Investigador Independiente; Guayaquil, Ecuador; dianischaguayb@ gmail.com

c. Médico; Investigador Independiente; Guayaquil, Ecuador; efrenbarcoramirez@ outlook.es

d. Médico; Investigador Independiente; Guayaquil, Ecuador; jcarbop91@ gmail.com 


\section{Neoplasia Cervicouterina: diagnóstico y tratamiento}

Vol. 3, núm. 4., (2019)

Sheyla Tamara Luna Martillo; Diana Nathaly Chaguay Blacio; Efrén Bryan Barco Ramírez; Jorge Andrés Carbo Palacio

\section{RESUMEN}

Las neoplasias cervicouterinas, enfermedad que también es conocidas como cáncer cervicouterino $(\mathrm{CCU})$, es aquella que ocurre cuando las células normales del cuello del útero comienzan a cambiar y crecen descontroladamente, proceso generalmente iniciado en las células de la superficie del cuello uterino donde además se encuentran dos tipos de células: las escamosas y las columnares, siendo las escamosas las que comúnmente las causantes de los mayores casos de este tipo de patología. El objetivo de esta revisión bibliográfica no ha sido que el de referir información vigente de las diversas fuentes que exponen sobre la neoplasia cervicouterina, su diagnóstico y tratamiento. La cantidad de resultados obtenidos tras esta investigación satisfizo bastamente la intención definida en el mencionado objetivo ya que fue evidente el hallazgo de fuentes referenciales de calidad que en síntesis sustentan la información presentada. Se concluye aludiendo nuevamente a la suficiente existencia de datos científicos y académicos que sustentan las respetables razones por las cuales esta patología es aun mundialmente reconocida como un problema de salud pública y un padecimiento muy común entre las mujeres, particularmente en aquellas que residen en países en vías de desarrollo, e igualmente, es reconocido que esta condición no ha dejado de despertar el interés de un constante estudio, puesto que el avance tecnológico y médico va de la mano, precisamente, con la evolución del diagnóstico y tratamiento.

Palabras Claves: Carcinomas, Displasia, Virus del papiloma humano, Extravasación de citostáticos, Fiebre neutropénica. 


\title{
Neoplasia Cervicouterina: diagnóstico y tratamiento
}

Vol. 3, núm. 4., (2019)

Sheyla Tamara Luna Martillo; Diana Nathaly Chaguay Blacio; Efrén Bryan Barco Ramírez;

Jorge Andrés Carbo Palacio

\begin{abstract}
Cervical neoplasms, a disease that is also known as cervical cancer (CCU), is one that occurs when normal cervical cells begin to change and grow uncontrollably, a process usually initiated in the cells of the surface of the cervix where it is also They find two types of cells: the squamous and the columnar, the squamous ones being the ones that commonly cause the greatest cases of this type of pathology. The objective of this bibliographic review has not been to refer current information from the various sources that expose about cervical neoplasia, its diagnosis and treatment. The amount of results obtained after this investigation satisfied the intention defined in the aforementioned objective, since the finding of referential sources of quality that in summary support the information presented was evident. It concludes by referring again to the sufficient existence of scientific and academic data that support the respectable reasons why this pathology is still recognized worldwide as a public health problem and a very common condition among women, particularly in those residing in countries where It is recognized that this condition has not ceased to arouse the interest of a constant study, since technological and medical advances go hand in hand, precisely, with the evolution of diagnosis and treatment.
\end{abstract}

Keywords: Carcinomas, dysplasia, human papillomavirus, cytostatic extravasation, neutropenic fever. 


\section{Neoplasia Cervicouterina: diagnóstico y tratamiento}

Vol. 3, núm. 4., (2019)

Sheyla Tamara Luna Martillo; Diana Nathaly Chaguay Blacio; Efrén Bryan Barco Ramírez; Jorge Andrés Carbo Palacio

\section{Introducción.}

Las neoplasias cervicouterinas, enfermedad también conocidas como cáncer cervicouterino (CCU). Según la Organización Panamericana de la Salud (OPS) es el cáncer más frecuente en mujeres en 45 países del mundo y mata a más mujeres que cualquier otra forma de cáncer en 55 países, entre ellos muchos países del África subsahariana, muchos de Asia (incluida la India) y algunos países centroamericanos y sudamericanos. (OPS, 2016)

El CCU, se origina a expensas del crecimiento incontrolado de las células que revisten el cuello del útero. Por su ubicación anatómica y las posibilidades de detección oportuna, si se detecta en sus etapas iniciales, este tipo de cáncer es prevenible en un $100 \%$, lo que garantiza una alta probabilidad de supervivencia y buena calidad de vida. Sin embargo, el CCU continúa siendo un problema de salud pública de gran magnitud a nivel mundial, y es una de las amenazas más graves para la vida de las mujeres. En la actualidad, se calcula que globalmente lo padecen más de un millón de personas, quienes en su mayoría ni han sido diagnosticadas, ni tienen acceso a un tratamiento que podría curarlas o prolongarles la vida. (Ruiz \& Medina, 2018, p. 3)

Nama et al. (2018) expresó que:

El cáncer es una de las principales causas de muerte a nivel mundial. El cáncer de cuello uterino es el cuarto cáncer más común en mujeres, con una estimación global de 528000 nuevos casos en 2012 (GLOBOCAN 2013). La gran mayoría (alrededor del 85\%) de la carga global está en los países de ingresos bajos y medios (PIBM), donde representa alrededor del $12 \%$ de todos los cánceres en las mujeres. El cáncer de cuello uterino es el 


\section{Neoplasia Cervicouterina: diagnóstico y tratamiento}

Vol. 3, núm. 4., (2019)

Sheyla Tamara Luna Martillo; Diana Nathaly Chaguay Blacio; Efrén Bryan Barco Ramírez; Jorge Andrés Carbo Palacio

cáncer más común en las mujeres en África oriental y central. Se calcularon unas 266000 muertes por cáncer de cuello uterino en todo el mundo en 2012, lo que representa el 7,5\% de todas las muertes debido al cáncer en las pacientes. Casi nueve de diez muertes debidas al cáncer uterino (87\%) ocurren en los países con menos recursos o de bajos ingresos. La mortalidad varía en hasta 18 veces entre las diversas partes del mundo, con tasas que varían desde menos de dos por 100.000 en Asia occidental, Europa occidental, y Australia/Nueva Zelanda hasta más de 20 por 100000 en Melanesia $(20,6)$, África central $(22,2)$ y África oriental $(27,6)$ (GLOBOCAN 2013). (p. 4)

De la misma manera, Suárez (2018) reportó que:

En la región de las Américas, 83,000 mujeres fueron diagnosticadas con CCU en el año 2012 y casi 36,000 murieron por esta causa. Las tasas de mortalidad fueron tres veces mayores en Latinoamérica y el Caribe que en Norte América. En Latinoamérica, las regiones con mayor incidencia de CCU en 2012 fueron Venezuela, Perú, Bolivia y Paraguay, mientras que Colombia y Brasil se encuentran en un punto medio, con incidencias entre 13.6 y 20.6 por 100,000 mujeres, y Chile es el país con menor incidencia (<7.9). En relación con la mortalidad, para el mismo año, Colombia, Brasil y Chile tuvieron tasas similares, entre 5.8 y 9.8 por 100,000 mujeres.

Este desarrollo investigativo se enfoca en la búsqueda, revisión y referenciación de la literatura cientificoacadémica reciente en torno a la neoplasia cervicouterína, cómo se diagnostica y cuáles serían sus formas de tratamiento, con la finalidad de asistir, no solo al personal de salud en cuanto a las herramientas vigentes de determinación de esta patología y su 


\section{Neoplasia Cervicouterina: diagnóstico y tratamiento}

Vol. 3, núm. 4., (2019)

Sheyla Tamara Luna Martillo; Diana Nathaly Chaguay Blacio; Efrén Bryan Barco Ramírez; Jorge Andrés Carbo Palacio

adecuado manejo, sino además contribuir con todo aquel interesado en un contenido bibliográfico de destacado valor, que le sirva de fundamento en el fortalecimiento del conocimientos, razones por las cuales a continuación se expondrá sobre; acepciones de fundamentales de neoplasias cervicouterinas, causas y factores de riesgo, síntomas, clasificación de los tipos de cáncer cercicouterino, prevención, diagnóstico y tratamiento.

\section{Materiales y Métodos.}

En base al objetivo de referir información reciente con respecto a las neoplasias cervicouterinas, su diagnóstico y tratamiento, para esta revisión se ha propuesto el desarrollo de una investigación de diseño documental, a nivel descriptivo.

Fundamentalmente se trató de la exploración de la literatura cientificoacadémica vigente, aprovechando para ello el uso de computadores personales y la internet como medios de acceso. Los términos de búsqueda empleados fueron las expresiones: neoplasias cervicouterinas, cáncer de cuello uterino y manejo de neoplasias cérvico-uterinas; así como también un equivalente en inglés: uterine cervical neoplasms. Las bases de datos que principalmente fueron utilizadas fueron: NCBI, BVS, Intramed, MedlinePlus, Cochrane, SciELO, entre otras.

El material bibliográfico que se seleccionó con preferencia estuvo caracterizado por concebirse como: artículos científicos, revisiones sistemáticas con o sin metaanálisis, tesis de grado, posgrado y doctorado, guías clínicas, e-books, consensos, protocolos, ensayos clínicos, noticias científicas, boletines y/o folletos de organismos con reconocida trayectoria en el ámbito cientificomédico, cientificoacadémico o de la salud; así como también otros tipos de documentos monográficos e informaciones que, a criterio propio, se valoró como útil por el valor de la 


\section{Neoplasia Cervicouterina: diagnóstico y tratamiento}

Vol. 3, núm. 4., (2019)

Sheyla Tamara Luna Martillo; Diana Nathaly Chaguay Blacio; Efrén Bryan Barco Ramírez;

Jorge Andrés Carbo Palacio

evidencia mostrada. De la misma manera, sólo se consultaron aquellos trabajos accesibles de manera gratuita y completa, y además, que hubiesen sido publicados entre 2009 y 2019, aunque igualmente hubo excepciones.

Bajo tales criterios, al comparar relativamente los resultados de las distintas bases de datos consultadas, la tendencia de los resultados osciló entre 19 y 177 fuentes referenciales, no obstante, en los casos de otras pesquisas complementarias efectuadas sin mayores filtros, que por cierto se inclinaban más al propio interés de encontrar toda aquella información igualmente importante para el desarrollo de la presente temática; los mismos fueron considerablemente superiores, en algunos casos superando las cinco centenas de registros, eventualidad que ineludiblemente requirió ser nuevamente resumida mediante otros criterios de selección, tales como: mayor correlación temática, relevancia, nivel de evidencia, entre otros.

Posterior a los procesos antes descritos, es cuando el equipo procedió con la aplicación de técnicas de estudio, tales como: lectura crítica y análisis de datos, interpretación y discusión de todos los documentos definitivamente escogidos, determinados como evidencia para este trabajo investigativo, sumario que sucesiva y definitivamente resultó en la fundamentación de las ideas referidas, que por cierto en todo momento se hizo bajo completo acuerdo.

Paralelamente, cabe destacar que todo aquel material que fue desestimado, respondió a un consenso del equipo investigador, y se fundamentó más que todo tras evaluar su contenido, entre esas se encuentran: cartas al editor, resúmenes, monografías de pregrado, anotaciones e incluso, algunos estudios de cohorte, reportes de casos, controles, series y otros tipos de textos. 


\section{Neoplasia Cervicouterina: diagnóstico y tratamiento}

Vol. 3, núm. 4., (2019)

Sheyla Tamara Luna Martillo; Diana Nathaly Chaguay Blacio; Efrén Bryan Barco Ramírez; Jorge Andrés Carbo Palacio

Finalmente, todas las opiniones encontradas, así como también las inclusiones y exclusiones de cada cita y/o referencia aquí expuesta, fueron igualmente resueltas de manera grupal, sin que se llegase a mantener algún disenso entre los autores.

\section{Resultados.}

El cáncer de cuello uterino se desarrolla cuando las células normales del cuello del útero comienzan a cambiar y crecen descontroladamente. La mayoría de los cánceres del cuello del útero son carcinomas de células escamosas; se llaman así por el tipo de células donde se ha originado. (Bover, 2017)

Gersten confirma que los CCU comienzan en las células de la superficie del cuello uterino, y en estas se encuentran dos tipos de células: las escamosas y las columnares, siendo las primeras nombradas las que, por lo general, son responsables de los casos de este tipo de enfermedad. Adicionalmente explica que:

El desarrollo del cáncer cervical generalmente es muy lento y comienza como una afección precancerosa llamada displasia. Esta afección se puede detectar por medio de una citología vaginal y es $100 \%$ curable. Pueden pasar años para que la displasia se convierta en cáncer cervical. La mayoría de las mujeres a quienes se les diagnostica cáncer cervical en la actualidad no se han sometido a citologías vaginales regulares o no han tenido un seguimiento por resultados anormales en estas. Casi todos los cánceres cervicales son causados por el virus del papiloma humano (VPH). El VPH es un virus común que se disemina a través de las relaciones sexuales. Existen muchos tipos diferentes (cepas) de VPH y algunas cepas llevan a cáncer cervical. Otras cepas pueden 


\section{Neoplasia Cervicouterina: diagnóstico y tratamiento}

Vol. 3, núm. 4., (2019)

Sheyla Tamara Luna Martillo; Diana Nathaly Chaguay Blacio; Efrén Bryan Barco Ramírez;

Jorge Andrés Carbo Palacio

causar verrugas genitales, mientras que otras no causan ningún problema en absoluto. (Gersten, 2017)

De igual forma, Suárez (2018) precisa que este "se origina en células con metaplasia en la zona de transformación del cérvix" posibilitando la presencia de desórdenes en los mecanismos de control celular, por factores cancerígenos externos, primordialmente por la infección crónica con las cepas de alto riesgo del VPH, además de la coexistencia de factores tales como tabaquismo, desnutrición, mala alimentación y enfermedades de transmisión sexual. (p. 102)

\section{Causas y Factores de Riesgo}

Mayo Clinic (2017) indica que esta patología inicia al generarse una mutación en las células normales, es decir, cuando un cambio genético las convierte en células anormales. Estas crecen y se multiplican sin control y no mueren, mientras que las normales crecen y se multiplican a una velocidad constante y, eventualmente, mueren en un momento determinado. La acumulación de células anormales es lo que produce una masa o tumor. Las células cancerosas invaden los tejidos aledaños y pueden desprenderse de un tumor para expandirse (formar metástasis) en otras partes del cuerpo.

Esta misma institución deja claro que aún no se ha determinado cuál es la causa del cáncer de cuello de útero, pero, definitivamente, el virus del papiloma humano (VPH) participa en el proceso. El VPH es muy frecuente, y la mayoría de las mujeres que tienen el virus nunca padecen cáncer de cuello de útero. Esto significa que otros factores, como, por ejemplo, el entorno o estilo de vida, también podrán determinar si una mujer lo padecerá. 


\section{Neoplasia Cervicouterina: diagnóstico y tratamiento}

Vol. 3, núm. 4., (2019)

Sheyla Tamara Luna Martillo; Diana Nathaly Chaguay Blacio; Efrén Bryan Barco Ramírez; Jorge Andrés Carbo Palacio

Bover resalta que:

El VPH está presente en más del 99\% de los casos de cáncer de cuello uterino. Este virus es una causa necesaria para el desarrollo del cáncer de cuello uterino y es el factor de riesgo más importante. El HPV se transmite de persona a persona durante las relaciones sexuales. Los factores que aumentan el riesgo de infección por HPV incluyen la actividad sexual a edad temprana, numerosos compañeros sexuales (o la relación sexual con un hombre que ha tenido muchas parejas) y la relación sexual con un hombre que tiene verrugas en el pene. La mayoría de las infecciones por VPH se resuelven espontáneamente. Se desconocen los motivos por los que sólo algunas infecciones progresan a alteraciones malignas. (Bover, 2017)

Continúa el autor exponiendo que, otros factores de riesgo pueden ser:

- Las mujeres cuyos sistemas inmunológicos están debilitados por el uso de ciertos medicamentos (corticosteroides, los usados tras trasplantes de riñón o terapia para otros tipos de cáncer o SIDA) corren más riesgos.

- Las mujeres con herpes genital tienen más riesgo de desarrollar cáncer de cuello uterino.

- Las mujeres con muchas parejas sexuales, o convivir con un varón con antecedentes de múltiples relaciones sexuales, tienen mayor riesgo de desarrollar cáncer de cérvix.

- Las mujeres que fuman tienen dos veces más riesgo de desarrollar cáncer de cuello uterino que las mujeres no fumadoras.

- El uso de anticonceptivos orales aumenta el riesgo de desarrollar cáncer de cérvix.

- El riesgo aumenta entre el final de la adolescencia y la mitad de los 30 años. Las mujeres 


\section{Neoplasia Cervicouterina: diagnóstico y tratamiento}

Vol. 3, núm. 4., (2019)

Sheyla Tamara Luna Martillo; Diana Nathaly Chaguay Blacio; Efrén Bryan Barco Ramírez; Jorge Andrés Carbo Palacio

de más de 40 años siguen en riesgo y deben continuar sometiéndose a exámenes para detección precoz (test de Papanicolau) con regularidad. (Bover, 2017)

Retomando el aporte de Mayo Clinic (2017), se puede verificar que coincide con parte de los factores antes mencionados, sin embargo, agrega que otros también pueden ser:

- Relaciones sexuales a temprana edad. Tener relaciones sexuales a temprana edad aumenta el riesgo de adquirir el virus del papiloma humano.

- Otras infecciones de transmisión sexual. Tener otras infecciones de transmisión sexual (como clamidia, gonorrea, sífilis y VIH/SIDA) aumenta el riesgo de adquirir el virus del papiloma humano.

- Sistema inmunitario débil. Las probabilidades de desarrollar cáncer de cuello uterino pueden ser mayores si tienes otra enfermedad que debilita el sistema inmunitario y tienes el virus del papiloma humano.

\section{Sintomas}

La OPS (2016) ha dejado ver que, en esencia, los síntomas dependerán de la etapa invasiva en la que se encuentre el cáncer cervicouterino, y estos pueden ser:

Tempranos:

- Flujo vaginal, a veces maloliente,

- Hemorragias irregulares (de cualquier tipo) en mujeres en edad fecunda.

- Oligometrorragia o hemorragia poscoital en mujeres de cualquier edad, inclusive jóvenes.

- Oligometrorragia o hemorragia posmenopáusica. 


\section{Neoplasia Cervicouterina: diagnóstico y tratamiento}

Vol. 3, núm. 4., (2019)

Sheyla Tamara Luna Martillo; Diana Nathaly Chaguay Blacio; Efrén Bryan Barco Ramírez; Jorge Andrés Carbo Palacio

- En caso de hemorragia perimenopáusica anormal, siempre se debe considerar la posibilidad de un cáncer cervicouterino, en particular si la hemorragia no responde al tratamiento apropiado.

Avanzados:

- Micción urgente o frecuente.

- Dolor de espalda.

- Dolor en la zona inferior del abdomen

- Dolor de espalda intenso.

- Pérdida de peso.

- Disminución del caudal urinario (por obstrucción uretral o insuficiencia renal).

- Pérdidas de orina o heces por la vagina (debido a fístulas).

- Tumefacción de los miembros inferiores.

- Disnea (debida a anemia o, rara vez, a metástasis pulmonares o derrame pleural). (p. 185)

Las alteraciones premalignas generalmente son asintomáticas. En las primeras etapas, el cáncer de cuello uterino puede ser asintomático. El primer síntoma de cáncer de cuello uterino generalmente es un sangrado vaginal anormal, con mayor frecuencia después de una relación sexual. Un manchado o una hemorragia más copiosa se puede producir entre ciclos menstruales. También los periodos pueden tener un sangrado excepcionalmente abundante. Los cánceres más avanzados con frecuencia causan hemorragia o una secreción vaginal maloliente y dolor en la zona pélvica. Si el cáncer está diseminado, puede causar dolor 


\section{Neoplasia Cervicouterina: diagnóstico y tratamiento}

Vol. 3, núm. 4., (2019)

Sheyla Tamara Luna Martillo; Diana Nathaly Chaguay Blacio; Efrén Bryan Barco Ramírez;

Jorge Andrés Carbo Palacio

lumbar e hinchazón de las piernas. El sistema urinario puede obstruirse, y sin tratamiento, producir una insuficiencia renal y la muerte. (Ramirez \& Salvo, 2017)

La Asociación Española Contra el Cáncer (AECC), aparte de coincidir con lo antes dicho, agrega que:

El dolor o las molestias durante las relaciones sexuales indican la existencia de problemas que deben ser consultados. Estos síntomas también pueden ser debidos a enfermedades benignas. Sin embargo si aprecias cualquiera de ellos es importante que acudas al especialista para el diagnóstico y tratamiento de su causa. (AECC, 2018)

\section{Clasificación}

Se basa en el grado de diseminación del cáncer:

- Estadio I: el cáncer está confinado al cuello uterino.

- Estadio II: el tumor se ha diseminado fuera del cuello uterino, incluyendo la parte superior de la vagina, pero todavía está dentro de la pelvis (que contiene los órganos reproductivos internos, la vejiga y el recto).

- Estadio III: el cáncer se ha diseminado por toda la pelvis y/o la parte inferior de la vagina y/o obstruye los uréteres y/o ocasiona trastornos renales.

- Estadio IV: el cáncer se ha diseminado fuera de la pelvis y/o a la vejiga o al recto o a órganos distantes. (Ramirez \& Salvo, 2017) 


\section{Neoplasia Cervicouterina: diagnóstico y tratamiento}

Vol. 3, núm. 4., (2019)

Sheyla Tamara Luna Martillo; Diana Nathaly Chaguay Blacio; Efrén Bryan Barco Ramírez; Jorge Andrés Carbo Palacio

En el mismo orden de ideas, (Suárez, 2018) detalla que:

El sistema de clasificación más común para asignar el estadio del tumor es el planteado por la Federación Internacional de Ginecología y Obstetricia (FIGO), el cual establece una clasificación basada en el TNM, donde la T se refiere al tamaño del tumor primario, $\mathrm{N}$ a la diseminación a ganglios linfáticos regionales y la $\mathrm{M}$ a las metástasis. Así, se observan cuatro estadios con subdivisiones, según las características del tumor y su grado de diseminación.

Tabla 1. Estadificación de la FIGO para el cáncer de cuello uterino para tumor primario (T)

\begin{tabular}{|l|c|}
\hline Características & $\begin{array}{c}\text { Estadio } \\
\text { FIGO }\end{array}$ \\
\hline $\begin{array}{l}\text { Carcinoma cervical confinado al útero (la extensión al cuerpo no debe ser tenida en } \\
\text { cuenta) }\end{array}$ & I \\
\hline $\begin{array}{l}\text { Carcinoma invasor diagnosticado solo mediante microscopía. Invasión del estroma } \\
\text { con una profundidad máxima de } 5 \mathrm{~mm} \text { y una extensión horizontal } \leq 7 \mathrm{~mm} \text {. El } \\
\text { compromiso del compartimento vascular, venoso o linfático no afecta la } \\
\text { clasificación. }\end{array}$ & I A \\
\hline Invasión estromal $\leq 3 \mathrm{~mm}$ en profundidad y $\leq 7 \mathrm{~mm}$ de extensión horizontal. & I A1 \\
\hline $\begin{array}{l}\text { Invasión estromal }>3 \mathrm{~mm} \text { y } \leq 5 \mathrm{~mm} \text { en profundidad, con una extensión horizontal } \\
\leq 7 \mathrm{~mm} .\end{array}$ & I A2 \\
\hline $\begin{array}{l}\text { Lesión clínicamente visible limitada al cuello uterino o lesión microscópica } \\
\text { mayores que el estadio IA. }\end{array}$ & I B \\
\hline Lesión clínicamente visible $\leq 4$ cm en su mayor diámetro. & I B1 \\
\hline Lesión clínicamente visible $>4 \mathrm{~cm}$ en su mayor diámetro. & I B2 \\
\hline $\begin{array}{l}\text { Carcinoma cervical que invade más allá del útero, pero no compromete la pared } \\
\text { pélvica o el tercio inferior de la vagina. }\end{array}$ & II \\
\hline Tumor sin invasión de parametrios. & II A \\
\hline Lesión clínicamente visible $\leq 4 \mathrm{~cm}$ en su mayor diámetro. & II A1 \\
\hline Lesión clínicamente visible $>4$ cm en su mayor diámetro. & II A2 \\
\hline Tumor con invasión de parametrios, sin llegar a la pared pelviana. & II B \\
\hline $\begin{array}{l}\text { Tumor que se extiende a la pared pélvica y/o compromete el tercio inferior de la } \\
\text { vagina y/o causa hidronefrosis o alteración de la función renal. }\end{array}$ & III \\
\hline $\begin{array}{l}\text { El tumor compromete el tercio inferior de la vagina, sin extensión a la pared } \\
\text { pélvica. }\end{array}$ & III A \\
\hline
\end{tabular}




\section{Neoplasia Cervicouterina: diagnóstico y tratamiento}

Vol. 3, núm. 4., (2019)

Sheyla Tamara Luna Martillo; Diana Nathaly Chaguay Blacio; Efrén Bryan Barco Ramírez;

Jorge Andrés Carbo Palacio

El tumor se extiende a la pared pélvica y/o causa hidronefrosis o alteración de la función renal.

El tumor invade la mucosa de la vejiga o del recto y/o se extiende más allá de la

pelvis (el edema bulloso no es suficiente para clasificar un tumor como T4).

III B

Nota. Álvarez et al. (2012), recuperado y adaptado de (Suárez, 2018)

\section{Prevención}

El cáncer cervical se puede prevenir haciendo lo siguiente:

- Recibir la vacuna contra el VPH. Previene la mayoría de los tipos de infecciones por el VPH que causan cáncer de cuello uterino. Su proveedor puede decirle si la vacuna es apropiada en su caso.

- Practicar relaciones sexuales con protección. El uso del condón durante la relación sexual reduce el riesgo de contraer el VPH y otras infecciones de transmisión sexual (ITS).

- Limitar la cantidad de compañeros sexuales que tenga y evitar las parejas que participen en actividades sexuales de alto riesgo.

- Hacerse citologías vaginales con la frecuencia que su proveedor le recomiende. Las citologías vaginales pueden ayudar a detectar cambios precoces, los cuales pueden tratarse antes de que se conviertan en cáncer cervical.

- Hacerse la prueba de VPH si así lo recomendó su proveedor. Puede usarse junto a la citología vaginal para buscar cáncer cervical en mujeres de 30 años en adelante.

- Si fuma, dejar de hacerlo. El consumo de cigarrillo aumenta las probabilidades de presentar cáncer cervical. (Gersten, 2017) 


\section{Neoplasia Cervicouterina: diagnóstico y tratamiento}

Vol. 3, núm. 4., (2019)

Sheyla Tamara Luna Martillo; Diana Nathaly Chaguay Blacio; Efrén Bryan Barco Ramírez; Jorge Andrés Carbo Palacio

\section{Diagnóstico}

La biopsia (obtención de una pequeña muestra de tejido para el análisis microscópico) es la que establece el diagnóstico definitivo de cáncer y el tipo histológico. Para el diagnóstico es preciso realizar una exploración física general y ginecológica exhaustiva, valorando tamaño y aspecto de los órganos pélvicos. El médico puede precisar de un examen pélvico bajo anestesia para valorar la posible extensión del tumor a útero, vagina, recto o vejiga. La cistoscopia y/o recto-sigmoidoscopia (exploración que permite visualizar y tomar biopsias dentro de la vejiga o recto) se podrá realizar, por indicación de su médico especialista, si hay sospecha de infiltración por el tumor de la vejiga de la orina o del recto. Radiografía de tórax: permite la exploración de los pulmones para valorar la posible diseminación tumoral a los mismos (metástasis pulmonares). La urografía (pielografia) permite visualizar las vías urinarias y vejiga mediante la inyección de contraste. La indicación la establecerá su médico especialista. El TAC (Tomografía Axial Computarizada) será solicitado asimismo por indicación del especialista. A pesar que es una exploración con importantes limitaciones en este tumor, en pacientes en las que no sea posible realizar un estadiaje quirúrgico puede ayudar a comprobar el estado de los ganglios. La RMN (Resonancia Magnética Nuclear) es la exploración radiológica que aporta más información para valorar la profundidad de invasión del tumor en el cérvix y también la posible infiltración de otras estructuras pélvicas (parametrios, vagina, recto, vejiga orina, etc.). La PET (Tomografía por Emisión de Positrones), consiste en inyectar moléculas de azúcar radioactivo en el cuerpo. Las células cancerosas absorben el azúcar con más rapidez que las células sanas, de forma tal que se iluminan en el PET. Esta exploración se puede utilizar para completar la información obtenida a través del estudio por TAC, RMN y el examen físico. Es el método más sensible para valorar la 


\section{Neoplasia Cervicouterina: diagnóstico y tratamiento}

Vol. 3, núm. 4., (2019)

Sheyla Tamara Luna Martillo; Diana Nathaly Chaguay Blacio; Efrén Bryan Barco Ramírez; Jorge Andrés Carbo Palacio

afectación de los ganglios linfáticos. La PET también es útil para diferenciar si, tras el tratamiento, persiste tumor o se trata de fibrosis (lesiones residuales no malignas). La gammagrafía ósea (valoración completa de los huesos) sólo se realizará si existe sospecha de afectación ósea. (Bover, 2017)

Instituciones como la Sociedad Estadounidense de Oncología Clínica (ASCO, por sus siglas en inglés) ha descrito que, para diagnosticar el cáncer de cuello uterino, se pueden aplicar las siguientes pruebas:

- Exploración ginecológica bimanual: la cual trata de la revisión del cuerpo de la mujer mediante la experticia médico a fines de detectar cualquier cambio inusual tanto en la vulva fuera del cuerpo como en el cuello uterino, el útero, la vagina, los ovarios y otros órganos cercanos. Esta prueba comúnmente se realiza en conjunto con la prueba de Papanicolaou.

- Prueba de Papanicolaou: consiste en la toma de muestras por parte del especialista, de las células mediante un ligero raspado de la parte externa del cuello uterino y la vagina. Dentro de este tipo de pruebas se encuentran la prueba de citología de base líquida, frecuentemente llamada ThinPrep o SurePath; y además están, los exámenes de detección por computadora, comúnmente denominados AutoPap o FocalPoint.

- Prueba de tipificación de VPH: es similar a la prueba de Papanicolaou.

- Colposcopia: relacionada al estudio visual mediante un instrumento especial llamado colposcopio, el cual, como lo haría un microscopio, permite el aumento de las células del cuello uterino y de la vagina, 


\section{Neoplasia Cervicouterina: diagnóstico y tratamiento}

Vol. 3, núm. 4., (2019)

Sheyla Tamara Luna Martillo; Diana Nathaly Chaguay Blacio; Efrén Bryan Barco Ramírez; Jorge Andrés Carbo Palacio

permitiendo al médico tratante obtener una mejor visualización e iluminación de los tejidos vaginales y del cuello uterino.

- Biopsia: referida a la extirpación de una cantidad pequeña de tejido para examinarlo a través de un microscopio, y estas pueden hacerse de varias formas, entre las que figuran: el raspado endocervical (endocervical curettage, ECC); la extirpación electroquirúrgica con asa (loop electrosurgical excision procedure, LEEP) o la conización (biopsia en cono) en la que se extrae un trozo de tejido con forma de cono del cuello uterino.

- Examen pélvico bajo anestesia: que no es más que la evaluación del área pélvica mientras la paciente se encuentra bajo anestesia para ver si el cáncer se ha diseminado a los órganos que están cerca del cuello uterino, incluidos el útero, la vagina, la vejiga o el recto.

- Radiografía: la cual se trata de un modo de crear una imagen de las estructuras internas del cuerpo usando una pequeña cantidad de radiación.

- Exploración por tomografía computarizada (Computed Tomography, CT) o por tomografía axial computarizada (Computed Axial Tomography, $C A T)$ : caracterizadas por el uso de ciertos equipos especiales que, con su propia computadora, va combinando las imágenes captadas por medio de rayos $\mathrm{X}$ del interior del cuerpo de la mujer desde varios ángulos, construyendo en fin una imagen tridimensional detallada que muestra las anomalías o los tumores. 


\section{Neoplasia Cervicouterina: diagnóstico y tratamiento}

Vol. 3, núm. 4., (2019)

Sheyla Tamara Luna Martillo; Diana Nathaly Chaguay Blacio; Efrén Bryan Barco Ramírez;

Jorge Andrés Carbo Palacio

- Imágenes por resonancia magnética (Magnetic Resonance Imaging, MRI): referida al equipo que usa campos magnéticos, en lugar de rayos $\mathrm{X}$, para producir imágenes detalladas del cuerpo.

- Estudio de tomografía por emisión de positrones (Positron Emission Tomography, PET) o PET-CT: comúnmente combinada con una exploración por CT, razón por la que se le denomina exploración por PET-CT, se trata de otra forma de crear imágenes de los órganos y los tejidos internos del cuerpo mediante el uso de usa sustancia radioactiva azucarada, la cual se inyecta en el cuerpo de la paciente que seguidamente es absorbida por las células que utilizan la mayor cantidad de energía (ya que el cáncer tiende a utilizar energía de manera activa, y por ende este absorbe una cantidad mayor de la sustancia radiactiva) y así puedan captarse dicha sustancia durante la exploración, identificación y captación en la generación de imágenes del interior del cuerpo. (ASCO, 2019)

\section{Tratamiento}

La importancia de la prevención de este tipo de cáncer y del acceso oportuno y continuo al tratamiento ha sido bastamente demostrada mediante las investigaciones de CCU. En ellos igualmente se han evidenciado que los programas de prevención coinciden en que esto es un problema de salud pública que influye de manera negativa en la vida personal, familiar, social y económica de las mujeres afectadas y de sus familias. (Ruiz \& Medina, 2018, págs. 3-4) 


\section{Neoplasia Cervicouterina: diagnóstico y tratamiento}

Vol. 3, núm. 4., (2019)

Sheyla Tamara Luna Martillo; Diana Nathaly Chaguay Blacio; Efrén Bryan Barco Ramírez; Jorge Andrés Carbo Palacio

Suárez (2018) indica que el uso de los distintos tratamientos reconocidos para esta enfermedad dependerá del estadio que se asigna al CCU, pero pueden ser: la conización, la braquiterapia, la radioterapia de haz externo, la quimioterapia, la traquelectomía o la histerectomía radical. Adicionalmente, aclara, también puede depender de: la etapa o estadio del cáncer, el tamaño y forma del tumor, la edad y salud general de la mujer y su deseo de tener hijos en el futuro.

Este experto asegura que la cura de un cáncer cervical precoz puede lograrse mediante la extirpación o destrucción de los tejidos precancerosos o cancerosos, y de allí es que las citologías vaginales de rutina se consideran trascendentales en la prevención de esta patología. Son varias las formas quirúrgicas de hacer la extirpación sin destruir el útero ni dañar el cuello uterino, para no comprometer la procreación eventualmente futura de la paciente.

Las cirugías para el cáncer cervical precoz pueden ser:

- Escisión electroquirúrgica con asa (LEEP, por sus siglas en inglés); que utiliza electricidad para extirpar el tejido anormal.

- Crioterapia; que congela las células anormales.

- Terapia con láser; la cual usa cierto tipo de luz para cauterizar el tejido anormal.

Una histerectomía (cirugía para extirpar el útero, pero no los ovarios) a menudo no se lleva a cabo para el cáncer cervical que no se ha diseminado. Se puede practicar en mujeres que se hayan sometido a procedimientos LEEP repetitivos. (Suárez, 2018) 


\section{Neoplasia Cervicouterina: diagnóstico y tratamiento}

Vol. 3, núm. 4., (2019)

Sheyla Tamara Luna Martillo; Diana Nathaly Chaguay Blacio; Efrén Bryan Barco Ramírez;

Jorge Andrés Carbo Palacio

Las cirugías para el cáncer cervical más avanzado incluyen:

- Histerectomía radical, con la cual se extirpa el útero y mucho de los tejidos circundantes, que incluyen los ganglios linfáticos y la parte superior de la vagina.

- Evisceración pélvica, un tipo extremo de cirugía en la cual se extirpan todos los órganos de la pelvis, incluyendo la vejiga y el recto.

Es posible utilizar la radioterapia para tratar los casos en que el cáncer se ha diseminado más allá del cuello uterino o el cáncer que ha reaparecido. (Suárez, 2018)

En este mismo orden de ideas, Nama et al. (2018) aporta que:

Tradicionalmente, los cánceres cervicouterinos tempranos se han tratado con cirugía y los cánceres avanzados con quimiorradioterapia. Sin embargo, no hay consenso con respecto al tratamiento ideal de los cánceres cervicouterinos estadio IB2 [ver Tabla 1], que están entre la enfermedad temprana y la avanzada. Alguno/as oncólogo/as ginecológico/as prefieren tratar estos cánceres con histerectomía radical y reservar la quimiorradioterapia para los que en la histología posterior demuestran tener alto riesgo de recidiva. (pág. 4)

La ASCO (2018) en este aspecto también ofrece un destacado aporte, dejando claro que los mismos dependen de varios factores, tales como, el tipo y estadio del cáncer, los posibles efectos secundarios, preferencias de la paciente y el estado de salud general, de hecho, afirman que dentro de la planificación de esta atención también se puede incluir tratamiento para síntomas y efectos secundarios, que son igualmente parte importante de la atención del cáncer. 


\section{Neoplasia Cervicouterina: diagnóstico y tratamiento}

Vol. 3, núm. 4., (2019)

Sheyla Tamara Luna Martillo; Diana Nathaly Chaguay Blacio; Efrén Bryan Barco Ramírez; Jorge Andrés Carbo Palacio

Este organismo se refiere primero a, la cirugía, que es otra cosa que la extirpación del tumor y de parte del tejido circundante sano durante una operación, pudiendo dentro de esta categoría encontrarse otras tales como: la conización; que consiste en el uso del mismo procedimiento que la biopsia en cono para extirpar todo el tejido anormal; el LEEP, que se trata del uso de una corriente eléctrica que se transmite a través de un gancho de alambre fino, con el que se extirpa el tejido; la histerectomía; (simple o radical) definida como la extirpación del útero y el cuello uterino, no obstante, la simple es la extirpación del útero y el cuello uterino, y la radical, es la extirpación del útero, el cuello uterino, la parte superior de la vagina, el tejido que rodea el cuello uterino y los ganglios linfáticos; la salpingooforectomía bilateral, cuando se extirpan ambos ovarios y ambas trompas de Falopio; la cervicectomía radical, que se trata de la extirpación del cuello uterino, sin ningún intrusión en el útero, más la disección de los ganglios linfáticos pélvicos; y en raras ocasiones de casos en los que este tipo de cáncer se ha diseminado más allá del cuello uterino, la exenteración pélvica, que se trata de la extirpación del útero, la vagina, el colon inferior, el recto o la vejiga.

Seguidamente, hacen referencia a: la radioterapia, siendo aplicada individualmente, antes de la cirugía o en sustitución de esta con el objetivo de disminuir el tamaño del tumor; se refiere al uso de rayos $\mathrm{X}$ u otras partículas con alta potencia para destruir las células cancerosas, encontrándose entre las más comunes la radioterapia de haz externo debido a que la radiación que se aplica desde una máquina externa al cuerpo humano.

Por último, hacen mención a: las terapias sistémicas, que no es otra cosa que la administración de medicamentos a través del torrente sanguíneo para destruir las células cancerosas en todo el cuerpo. Dentro de este grupo se ubican las quimioterapias, la terapia 


\section{Neoplasia Cervicouterina: diagnóstico y tratamiento}

Vol. 3, núm. 4., (2019)

Sheyla Tamara Luna Martillo; Diana Nathaly Chaguay Blacio; Efrén Bryan Barco Ramírez; Jorge Andrés Carbo Palacio

dirigida y la inmunoterapia (o terapia biológica), que igualmente pueden ser aplicadas de manera conjunta o individual. La quimioterapia se refiere al uso de fármacos para destruir las células cancerosas, generalmente al evitar que las células cancerosas crezcan, se dividan y produzcan más células; la terapia dirigida es un tratamiento que se dirige a los genes o a las proteínas específicos del cáncer, o a las condiciones del tejido que contribuyen al crecimiento del cáncer y la supervivencia; y la terapia biológica, es aquella que usa para estimular las defensas naturales del cuerpo, es decir, es la que aprovecha los materiales producidos por el cuerpo o fabricados en un laboratorio para mejorar, dirigir o restaurar la función del sistema inmunitario. (ASCO, 2018)

Complicaciones del tratamiento contra las neoplasias cervicouterinas:

- Extravasación de citostáticos.

- Náuseas y vómitos.

- Dermatitis por fármacos que inhiben el receptor del factor de crecimiento epidérmico (EGFR).

- Radiodermitis y mucositis por radiación.

- Fiebre neutropénica.

- Síndrome de lisis tumoral. (Medicina Interna Basada en la Evidencia, 2019)

Finalmente, un dato que bien valdría la pena resaltar es el indicado por la especialista Adriana Alvarado Zermeño en perspectivas de la celebración del reciente $37^{\circ}$ Congreso Nacional de Oncología de la Sociedad Mexicana de Oncología (SMeO). Respecto al CCU, la experta, quien a su vez ha sido citada por Vidal (2019), asegura que "...la radioterapia continúa siendo un componente importante del manejo curativo de estos tumores, en particular de cáncer de 


\section{Neoplasia Cervicouterina: diagnóstico y tratamiento}

Vol. 3, núm. 4., (2019)

Sheyla Tamara Luna Martillo; Diana Nathaly Chaguay Blacio; Efrén Bryan Barco Ramírez; Jorge Andrés Carbo Palacio

cérvix...".

Por su parte, Vidal (2019) refiere que:

El avance de las tecnologías y los descubrimientos médicos ha posibilitado que día con día los tratamientos para el cáncer sean mucho más personalizados en la búsqueda por evitar efectos adversos o toxicidades innecesarias. Aunque actualmente existen guías estandarizadas de tratamiento, decidir la técnica y el régimen del paciente no es un tema sencillo, y depende no solo del tipo de neoplasia y la etapa en que se encuentre, sino de las características particulares del paciente, como edad, posibilidad de acceso a las terapias y tasa de recurrencia, entre otras.

\section{Conclusiones.}

Tanto los registros estadísticos como la creciente literatura entorno a esta penosa enfermedad evidencian las considerables razones por las cuales esta patología es aun mundialmente reconocida como un problema de salud pública y un padecimiento muy común entre las mujeres, particularmente en aquellas que residen en países en vías de desarrollo.

Paralelamente puede llegarse igualmente a deducir que esta condición no ha dejado de despertar el interés de su constante estudio puesto que el avance tecnológico y médico va de la mano, precisamente, con la evolución del diagnóstico y tratamiento. 


\section{Neoplasia Cervicouterina: diagnóstico y tratamiento}

Vol. 3, núm. 4., (2019)

Sheyla Tamara Luna Martillo; Diana Nathaly Chaguay Blacio; Efrén Bryan Barco Ramírez; Jorge Andrés Carbo Palacio

\section{Bibliografía.}

AECC. (2018). AECC [Asociación Española Contra el Cáncer]. Recuperado el 25 de 11 de 2019, de aecc.es/es: https://www.aecc.es/es/todo-sobre-cancer/tipos-cancer/cancercervix/sintomas-cancer-cervix

ASCO. (2018). American Society of Clinical Oncology. Recuperado el 25 de 11 de 2019, de cancer.net/es: https://www.cancer.net/es/tipos-de-c\%C3\%A1ncer/c\%C3\%Alncer-decuello-uterino/tipos-de-tratamiento

ASCO. (Febrero de 2019). Cancer. Recuperado el 25 de 11 de 2019, de cancer.net: https://www.cancer.net/es/tipos-de-c\%C3\%A1ncer/c\%C3\%A1ncer-de-cuellouterino/diagn $\% \mathrm{C} 3 \% \mathrm{~B} 3$ stico

Bover, I. (09 de Marzo de 2017). SEOM [Sociedad Española de Oncología Médica]. Recuperado el 25 de 11 de 2019, de https://seom.org/: https://seom.org/info-sobre-elcancer/cervix?showall $=1$

Gersten, T. (21 de Octubre de 2017). Cáncer cervical. (A.D.A.M., Editor) Recuperado el 25 de 11 de 2019, de https://medlineplus.gov/spanish/ency/article/000893.htm

Mayo Clinic. (23 de Agosto de 2017). Mayo Clinic. Recuperado el 25 de 11 de 2019, de mayoclinic.org: https://www.mayoclinic.org/es-es/diseases-conditions/cervicalcancer/symptoms-causes/syc-20352501

Medicina Interna Basada en la Evidencia. (2019). Empendium. Recuperado el 25 de 11 de 2019, de empendium.com: https://empendium.com/manualmibe/chapter/B34.II.22.2.

Nama, V., Angelopoulos, G., Twigg, J., Murdoch, J., Bailey, J., \& Lawrie, T. (2018). Histerectomía radical tipo II o tipo III en comparación con la quimiorradioterapia como intervención primaria para el cáncer de cuello uterino en estadio IB2. Cochrane Database of Systematic Reviews, 10(CD011478), 15 pp. doi:10.1002/14651858.CD011478.pub2.

OPS. (2016). Control integral del cáncer cervicouterino Guía de prácticas esenciales. (O. P. Salud, Ed.) Washington, DC: OMS. Recuperado el 25 de 11 de 2019

Ramirez, P., \& Salvo, G. (Noviembre de 2017). Manual MSD. Recuperado el 25 de 11 de 2019, de https://www.msdmanuals.com/es: https://www.msdmanuals.com/es-ve/hogar/saludfemenina/c\% $\% 3 \% \mathrm{~A} 1$ nceres-del-aparato-reproductor-femenino/c\% $3 \% \mathrm{~A} 1$ ncer-delcuello-uterino

Ruiz, D., \& Medina, M. (2018). Atención en salud de mujeres con lesiones precursoras de cáncer de cuello uterino : evidencia cualitativa de la fragmentación del sistema de salud en Colombia. Pontificia Universidad Javeriana. Cali: Pontificia Universidad Javeriana. $\begin{array}{lllllll}\text { Recuperado el } & 25 & \text { de } & 11 & \text { de } & 2019, & \text { de }\end{array}$ 


\section{Neoplasia Cervicouterina: diagnóstico y tratamiento}

Vol. 3, núm. 4., (2019)

Sheyla Tamara Luna Martillo; Diana Nathaly Chaguay Blacio; Efrén Bryan Barco Ramírez; Jorge Andrés Carbo Palacio

http://vitela.javerianacali.edu.co/bitstream/handle/11522/11488/Atencion_salud_mujeres. pdf? sequence $=1 \&$ is Allowed $=y$

Suárez, F. (Julio de 2018). Terapéutica del cáncer de cuello uterino, una revisión de la literatura. Med UNAB, 21(1), 100 - 114. doi:doi.org/1029375/01237047.2583

Vidal, M. (13 de Noviembre de 2019). Medscape. Recuperado el 25 de 11 de 2019, de https://espanol.medscape.com/verarticulo/5904716

$$
\text { (9) (1) } \Theta(0
$$

RECONOCIMIENTO-NOCOMERCIAL-COMPARTIRIGUAL

CC BY-NC-SA

ESTA LICENCIA PERMITE A OTROS ENTREMEZCLAR, AJUSTAR Y CONSTRUIR A PARTIR DE SU OBRA CON FINES NO COMERCIALES, SIEMPRE Y CUANDO LE RECONOZCAN LA AUTORÍA Y SUS NUEVAS CREACIONES ESTÉN BAJO UNA LICENCIA CON LOS MISMOS TÉRMINOS. 